\title{
Plasenta yapışma anomalileri: Klinik yaklaşım ve yönetim
}

\author{
Morbidly adherent placenta: Clinical approach and management \\ Serkan Kahyaoğlu*, Şevki Çelen, İnci Kahyaoğlu, Leyla Mollamahmutoğlu, Nuri \\ Danıșman
}

Kadın Hastalıkları ve Doğum Kliniği (Dr. S. Kahyaoğlu, Dr. İ. Kahyaoğlu, Dr. L. Mollamahmutoğlu), Zekai Tahir Burak Kadın Sağlığı Eğitim ve Araştırma Hastanesi, TR-06100 Ankara. Kadın Hastalıkları ve Doğum Kliniği (Doç. Dr. Ş. Çelen, Doç. Dr. N. Danışman), Etlik Kadın Sağlı̆̆ı Eğitim ve Araştırma Hastanesi, TR-06010 Ankara

\begin{abstract}
Özet
Önceki sezaryan doğumları takibeden gebeliklerde obstetrik riskler artmıştır. Anormal plasentasyon oluşumları olarak plasenta akreta ve sezaryan skar gebelikleri iki önemli klinik durumdur. Plasenta akreta; plasentanın uterin kaviteye desidua bazalisin yokluğu nedeni ile anormal bir şekilde yapışması ve fibrinoid tabakanın inkomplet gelişimi ile karakterize bir tanıdır. Plasenta previa ile komplike olan gebeliklerin \%5-10'unda plasenta akreta olur. Plasental implantasyonun daha ciddi anormallikleri, koryonik villusların myometriyum içine kadar invaze olduğu plasenta inkreta ve koryonik villusların uterus serozasını penetre ettiği plasenta perkretadır. 1950'li yıllarda yaklaşık 30.000 doğumda bir görülen plasenta akretanın insidansı son yıllarda artan sezaryan ile doğumların prevelansındaki artışa paralel olarak 553 ile 2510 doğumda bir görülmeye başlamıştır. Plasenta akretanın en önemli risk faktörü önceki geçirilmiş uterus cerrahisidir. Alt uterin segmentin skarlı alanındaki ince, kötü oluşan veya olmayan desidua bazalis tabakasının trofoblastların derin penetrasyonuna direnç gösterememez ve plasenta önceki uterin cerrahiye bağlı olarak travmatize olan uterusun patolojik bir bölgesini invaze eder. Anormal plasental implantasyon doğumu takiben plasentanın normal ayrılmasına engel olur. Plasenta akretanın ilk klinik bulgusu manuel plasenta ayrılması girişimi sırasında meydana gelen aşırı ve hayatı tehdit eden kanamadır. Plasenta akretaya renkli dopler modalitelerini de içeren prenatal ultrason muayenesindeki karakteristik bulguların varlığı ile tanı konur. Şüpheli vakalarda manyetik rezonans görüntüleme yararlı olur. Masif kanama ve bunun sonucunda gelişebilen dissemine intravasküler koagülasyon, erişkin respiratuar distres sendromu, böbrek yetmezliği, planlanmamış cerrahi ve ölüm plasenta akretanın en ciddi komplikasyonlarıdır. Plasenta akretanın preoperatif ve intraoperatif yönetim stratejileri bu derlemede detaylı olarak ele alınmıştır.
\end{abstract}

Anahtar sözcükler: Plasenta akreta, yönetim, klinik yaklaşım, tedavi stratejileri

\begin{abstract}
Obstetric risks have increased among pregnancies following previous cesarean section deliveries. Placenta accreta and cesarean scar pregnancies, as abnormal placentation entities, represent two important clinical manifestations. Placenta accreta is characterised with a placenta that is abnormally adherent to uterine cavity because of the absence of decidua basalis and presence of incompletely developed fibrinoid layer. Placenta accreta occurs in 5-10\% of pregnancies complicated with placenta previa. Placenta increta and percreta are the other serious abnormalities of placental implantation that demonstrates invasion of chorionic villi into the myometrium and uterine serosa respectively. Placenta accreta has been seen rarely as 1 in 30.000 births in 1950's but the incidence of placenta accreta has increased recently to 1 in 553 and 2510 deliveries in parallel with increased cesarean sectio deliveries. Previous uterine surgery is the most important risk factor for placenta accreta. Thin, defectively formed or absent decidua basalis layer can not show resistance to deep penetration of trophoblasts and placenta invades this pathological region of uterus that has previously been traumatised by uterine surgery. Abnormal placental implantation impedes placental removal spontaneously following delivery. The first clinical sign of placenta accreta is profuse and life threatening bleeding that occurs during manuel removal of placenta. Placenta accreta is diagnosed with characteristic signs during prenatal ultrasound examination including color doppler modalities. Magnetic resonance imaging is also helpful for equivocal cases. Massive bleeding and resultant disseminated intravascular coagulation, adult respiratuar
\end{abstract}


distress syndrome, renal insufficiency, unplanned surgery and death are serious complications of placenta accreta. Preoperative and intraoperative management strategies of placenta accreta have been detailed in this review.

Keywords: Placenta accreta, management, clinical approach, treatment strategies

Geliş tarihi/Received: 15 Ocak 2012; Kabul tarihi/Accepted: 12 Mayıs 2013

*İletişim adresi:

Dr. Serkan Kahyaoğlu, Kadın Hastalıkları ve Doğum, Zekai Tahir Burak Kadın Sağlığı Eğitim ve Araştırma Hastanesi, TR-06100 Ankara. E-posta: mdserkankahyaoglu@gmail.com

\section{Giriş \\ Patofizyoloji}

Son yıllarda artan sezaryan oranlarına bağlı olarak geçirilmiş sezaryan sayısı ile doğru orantılı bir biçimde sonraki gebeliklerde plasenta yapışma anomalilerinin görülme insidansı artmıştır. Geçmişte nadir görülen bu patolojik durum ile kadın doğum hekimleri daha sıklıkla karşılaşmaktadırlar. Maternal ve fetal morbidite ve mortaliteyi artıran plasenta yapışma anomalilerinin uygun klinik yönetiminin, medikal ve özellikle cerrahi tedavi yaklaşımlarının bilinmesi önem taşımaktadır. Plasenta yapışma anomalileri son yıllarda sezaryanda histerektomi gerektiren klinikopatolojik durumlar içerisinde ön plana çıkmıştır. İngiltere obstetrik tarama sistemi (UKOSS) verilerine göre obstetrik nedenli histerektomi yapılan hastaların yaklaşık \%39'unun sebebi plasenta yapışma anomalileridir [1]. Bu tür hastaların doğumu kadın doğum uzmanı, anestezi uzmanı, ürolog, jinekolojik onkolog ve kalp damar cerrahından oluşan multidisipliner yaklaşım gerektirebilir. Geçirilmiş sezaryan öyküsü olan, uterin dilatasyon ve küretaj gibi myometriyumu hasarlandıran cerrahi girişimler geçiren hastalarda hem plasenta previa hem de plasenta yapışma anomalilerinin görülme riski arttığından prenatal takip döneminde plasenta previası olan, renkli dopler incelemesinde plasental damarlanma artışı olan ve plasenta ile mesane arasındaki uterin myometriyumun hipoekoik bir alan olarak tespit edilemeyen hastalarda plasenta yapışma anomalisinden şüphelenilip bu tür hastaların kan ve kan ürünlerinin temin edilebildiği, gerektiğinde multidisipliner yaklaşımın sağlanabildiği merkezlere transferi önem arzetmektedir. Elektif olarak obstetrik histerektomi olan hastalara göre acil obstetrik histerektomi olan hastalarda intraoperatif kan kaybı ve kan transfüzyonu gereksinimi daha fazladır. Özellikle daha önceki doğumlarını sezaryan ile yapan kadınlarda takibeden gebeliklerde plasenta previa ve plasenta yapışma anomalileri açısından değerlendirilmeleri, plasentasyon anomalisinden şüphelenilen hastaların doğumlarını obstetrik kanamanın uygun yönetilebileceği merkezlerde ve obstetrik kanamanın cerrahi tedavi modalitelerine hakim olan klinisyenlerin gözetiminde yapmaları çok önemlidir.

Plasenta ovulasyondan 13-15 gün sonra oluşmaya başlar. Fetal periyodun başlaması ile beraber desidua kapsilarisin üzerini kaplayan villuslar koryon leaveyi oluşturmak üzere dejenere olurken desidua bazalisin üzerindeki villuslar plasentayı oluşturmak için prolifere olurlar. Plasentanın normal implantasyonu gebeliğin başarısı için gereklidir ve sıkı bir şekilde regule edilir. Sitokinler, steroid hormonlar, immünolojik faktörler, prostaglandinler ve diğer bazı mediatörler başarılı plasentasyon için gereklidir [2]. Embriyo relatif olarak hipoksik bir ortamda gelişir. Prolifere olan sitotrofoblastların bazal laminaları erken gebelikte embriyoya oksijen difüzyonunu azaltacak şekilde kalındır. İntervillöz boşluğa kan akımı 10-12. gebelik haftasına kadar başlamaz. Bu fizyolojik hipoksik ortam diğer birçok hücre tipinin aksine sitotrofoblastlarda mitozda artışa yol açar. Sezaryan skar bölgesinin relatif olarak kanlanmasının azalmış, avasküler- aselüler bir bölge olmasından dolayı sezaryan sonrası plasenta previa ve akreta oranlarında artışa yol açacak şekilde embriyo için atraktif bir bölge olabilir $[3,4]$. 
Plasenta akretanın en önemli risk faktörü önceki geçirilmiş uterus cerrahisidir ve sezaryan ile sonuçlanan önceki bir doğumdan sonraki gebelikte plasenta previa tespit edilmesi en s1k klinik prezentasyonudur. Anormal implantasyonun mekanizmas1 alt uterin segmentin skarlı alanındaki defektif desidua bazalis tabakasının trofoblastların derin penetrasyonuna direnç gösterememesidir. Maternal yaşın $35^{\prime}$ 'in üzerinde olması, paritede artış, endometrial defektler, önceki geçirilmiş myomektomi, plasentanın elle çıkartılması, histeroskopik cerrahi, pelvik radyasyon tedavisi ve submuköz leiyomyom varlığı diğer risk faktörleridir [2]. Endometrial ablasyon ve uterin arter embolizasyonu sonrası plasenta akreta vakaları bildirilmiştir $[5,6]$.

Önceki obstetrik hikayesine göre plasenta previalı bir kadında plasenta akreta riski şu şekildedir: Skarsız uterus: \%1-5, önceki bir sezaryan: \%11-25, önceki iki sezaryan: \%3547, önceki üç sezaryan: \%40, önceki dört veya daha fazla sezaryan: \%50-67 [2, 7, 3].

Plasenta previa bulunmasa bile artan sezaryan sayısı ile korele olarak plasenta akreta riski de artmaktadır. Akreta riski bir, iki, üç, dört, beş ve altı veya daha fazla önceki geçirilmiş sezaryan doğumdan sonraki gebelikte sırasiyla \% 0.24, 0.32, 0.57, 2.13, 2.33, 6.74'dür [3]. Histerektomi riski bir kadının dördüncü sezaryanı ise $\% 2.5$, altı ve daha fazla sezaryan olmuşsa \%9'dur. Plasenta akretanın doğum eylemi gelişmeden yapılan sezaryanlardan sonraki gebeliklerde daha sıklıkla gelişip gelişmediği hakkında net bilgiler yoktur.

Anormal plasental implantasyon doğumu takiben plasentanın normal ayrılmasına engel olur. Plasenta yapışma anomalilerinin ilk klinik bulgusu manuel plasenta ayrılması girişimi sırasında meydana gelen genellikle aşırı ve hayatı tehdit eden kanamadır. Plasentanın bir kısmı veya tamamı uterin kaviteye yapışıktır ve ayrılma yüzeyi gelişmez. Mesane invazyonu ile birlikte olan plasenta perkreta gebelikte hematüriye neden olabilir.

\section{TanI}

Plasenta yapışma anomalilerinin prenatal tanısı ultrason muayenesindeki karakteristik bulguların varlığı ile konur. Ultrasonun yüksek riskli hastalarda (önceki geçirilmiş sezaryan ve plasenta previası olan hastalar) plasenta akretayı tanımadaki sensitivite ve spesifitesi sirasıyla \%80 ve \%95'tir [8-10]. Ultrason bulguları kesin olmadığında manyetik rezonans (MR) görüntüleme faydalı olabilir. Plasental implantasyonun normal ultrasonografik görüntüsünün varlığı nadiren patolojik plasental invazyon ile ilişkilidir. Retrospektif bir çalışmada, plasenta akreta tanısı doğum öncesi konulan kadınlarda tanının intrapartum konulduğu kadınlara göre daha az kan kaybı ve daha az transfüzyon gereksinimi olduğu görülmüştür [11].

Normal plasental implantasyonda, mesane duvarının devamlılığı plasenta ile arasındaki bir hipoekoik alan ve homojen bir plasenta görünümü mevcuttur. Plasenta akreta varlığında bu hipoekoik sınır kaybolmuştur ve plasenta mesane ile devamlı olarak görülür. Uterin duvarın hemen yanında intraplasental sonolusen boşluklar (venöz göllenmeler ve plasental lakünalar: İsviçre peyniri görüntüsü) görülmesi plasenta akretay1 güçlü bir şekilde düşündürtür [11-13] (Şekil 1). Plasenta akretalı ve önceki bir sezaryan doğumu olan 7 hastada yapılan bir çalışmada bunların 6 tanesinde gestasyonel kesenin 10 hafta veya daha önceki gebelik haftalarında fundus yerine alt uterin segmente yerleşmiş olduğu görülmüştür [14]. Patolojik sonuçlara bakıldığında 16 haftalıkken bile gelişmiş olan plasenta perkreta vakaları bildirilmiş olması plasenta akretadan perkretaya doğru zaman bağımlı bir geçiş olmadığını göstermektedir. 


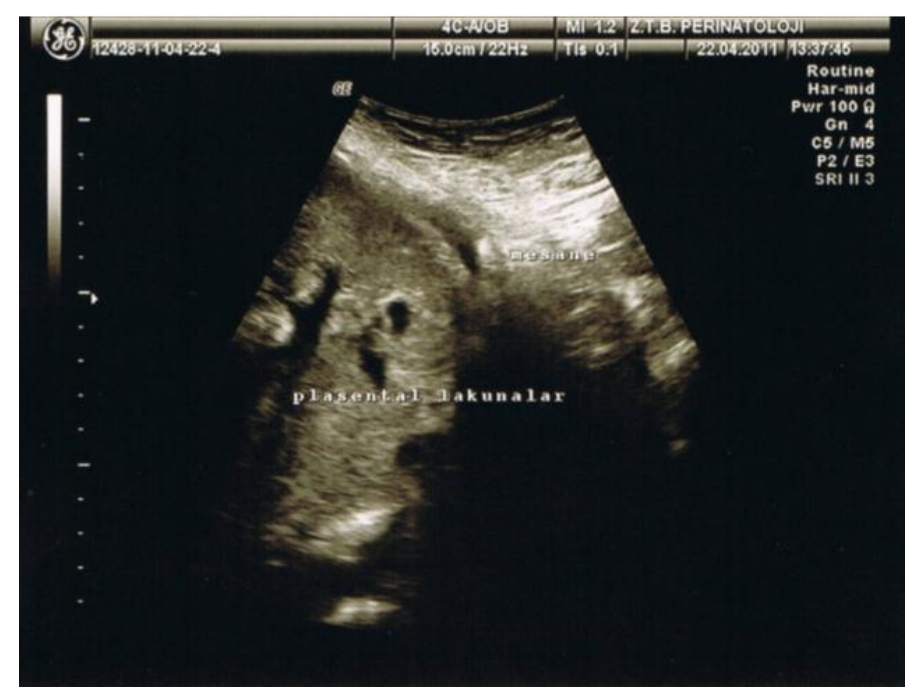

Şekil 1. Transabdominal ultrasonografide sagittal kesitte bir plasenta previa vakasında plasenta akretayı düşündüren plasental lakünaların varlığı (İsviçre peyniri görünümü).

Plasenta akretanın renkli dopler ultrasonografideki bulguları şunları içerir (Şekil 2):

- Difüz ve fokal intraparankimal plasental lakünar akım

- Mesane ve uterin serozanın hipervaskülaritesi

- Subplasental venöz komplekste belirginleşme

- Subplasental dopler vasküler sinyal kaybı

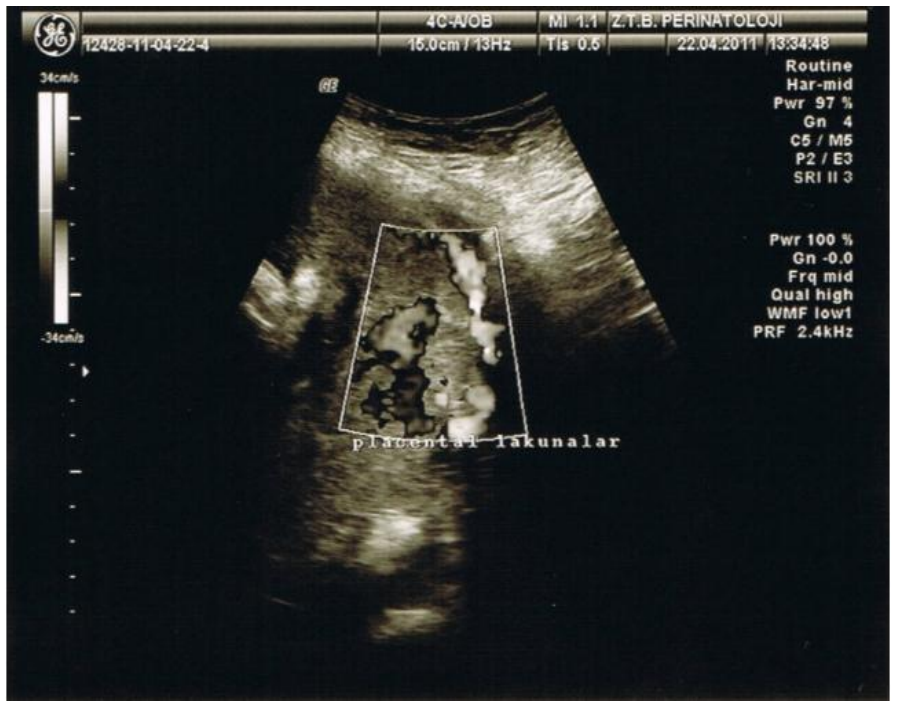

Şekil 2. Transabdominal renkli dopler ultrasonografide difüz ve fokal intraparankimal plasental lakünar akım ve subplasental venöz komplekste belirginleşme.

Bir çalışmada önceden sezaryan ile doğum yapmış hastanın plasental myometriyal invazyonu öngörmek için yapılan renkli dopler ultrsanografisinde, myometriyumun kalınlığının $1 \mathrm{~mm}$ 'den kısa olması veya büyük intraplasental göllerin varlığının myometriyal invazyonu öngörme açısından \%100 sensitivite, $\% 72$ spesifite, $\% 72$ pozitif prediktif değer ve \%100 negatif prediktif değere sahip olduğu tespit edilmiştir [15].

Ultrason bulguları kesin olmadığında MR görüntüleme faydalı olabilir. Özellikle de mesanenin görüntüsünden yararlanılamayan posterior yerleşimli plasenta akretayı tespit 
etmede plasental- myometriyal birleşim yerinin değerlendirilmesinde ve myometriyal, parametriyal ve mesane invazyonunun boyutunu tespit etmede faydalıdır [16, 17]. MR bulgularından en faydalı olanları; mesaneye doğru uterin balonlaşmanın, plasenta içinde heterojen sinyal yoğunluğunun ve T2 imajlarında intraplasental bandların tespit edilmesidir [18, 19].

Başka nedenlerle açılanamayan maternal serum alfa-fetoprotein (MSAFP) konsantrasyonu artışı ile plasenta akreta arasındaki ilişkiyi gösteren vaka serileri vardır [20-22]. Bir çalışmada plasenta akreta/inkreta/perkreta vakalarının \%45'inde MSAFP $\geq 2.5$ MOM olarak bulunmuştur [20]. MSAFP'nin normal sınırlarda olması plasenta akreta tanısinı ekarte ettirmez.

Plasenta akreta vakalarında maternal serum kreatinin kinaz ve beta hCG seviyelerinde artış bildirilmiştir. Mazouni ve ark. [23] maternal kanda cell-free fetal DNA, plasental mRNA değerlendirilmesi ve plasental spesifik genler için DNA mikroarray kullanılmasının faydalı olacağını belirtse de bunların kullanımının klinik olarak faydasını kanttlayan yeterli bilgi yoktur.

\section{Komplikasyonlar}

Plasenta yapışma anomalilerinin en sık komplikasyonu masif kanamadır ve bunun sonucunda gelişebilen sekeller dissemine intravasküler koagülasyon, erişkin respiratuar distres sendromu, böbrek yetmezliği, planlanmamış cerrahi ve ölümdür. Peripartum histerektominin en sık sebeplerinden biri plasenta akreta olmuştur [21, 24, 25]. Mesane invazyonu olan 54 plasenta perkreta vakasında yapılan bir literatür derlemesinde 17 vakada hematüri saptanmıştır. Vakaların 12 tanesinde sistoskopi yapılmıştır fakat tanıda faydalı olmamıştır. Vakaların 24 tanesinde parsiyel sistektomi gerekmiştir. Sistoskopi veya cerrahi esnasinda sistotomi yapılması mesane veya üreteral tutulumun derecesini belirlemede yardımcı olabilir [26]. Plasenta perkreta olgularında masif kan transfüzyonu, enfeksiyon, perinatal ölüm, maternal ölüm, üreteral ligasyon veya fistül formasyonu ve spontan uterin ruptür gibi komplikasyonların görülme olasılığı daha yüksektir [27].

\section{Preoperatifyaklaşım}

Plasenta yapışma anomalilerinde preoperatif dönemde amaç hastaya yeterli bilgi vermek ve klinik tablo ile ilişkili olabilecek masif kanama, morbidite ve mortaliteyi azaltacak gerekli önlemleri almaktır. Plasenta akreta vakalarında intraoperatif medikal ve cerrahi tedavilerle kanamayı durdurmak mümkün olabilse de özellikle plasenta inkreta ve perkreta vakalarında plasenta genellikle ayrılmadığından dolayı sezaryan histerektomi kaçınılmaz olabilir [22, 21, 24]. Eğer plasenta yerinde bırakılırsa subinvolüsyona sekonder postpartum kanama meydana gelebilir.

Doğum; obstetrik kanamaya yaklaşımda tecrübeli personel ve gerekli şartların sağlandığı bir yerde planlanmalıdır. Planlı doğum acil doğuma göre daha az intraoperatif kan kaybı ile ilişkilidir. Bir yaklaşıma göre fetal akciğer matüritesi 35-36. gebelik haftasında bakılıp test matür çıkması halinde doğum planlanabilir. Büyük bir vaka serisinde bu yaklaşımda belirgin neonatal morbidite saptanmamıştır [10]. Obstetrik hastalarda henüz çok tecrübe olmamasına rağmen, preoperatif dönemde normovolemik hemodilüsyon ile kırmızı küre hücrelerinin yerine kristaloid veya kolloid sıvı koyarak bazal hematokrit düşürülüp intraoperatif kanama esnasında daha az kırmızı küre kaybı ve dolayısıyla daha az homolog kan transfüzyonu gereksinimi ve hazır durumda otolog kan ürününün bulunması sağlanabilir [28-31].

Plasenta yapışma anomalileri vakalarında internal ilyak arterin balon oklüzyonu veya uterin arter embolizasyonu; mesane flepinin mobilizasyonu ve alt uterin segmentin diseksiyonu sırasında kanamayı önlemek amaciyla yapılabilir [32-39]. İnternal iliak arterin balon oklüzyonunun kan kaybını, kan transfüzyonu gereksinimini ve ameliyat süresini kısalttığı yönünde çalışmalar olmasına rağmen bazı diğer çalışmalarda da faydası gösterilememiştir [31-34, 40]. Balon oklüzyonu işlemi, floroskopi eşliğinde balon kateterlerin bilateral femoral arterler yoluyla retrograd olarak preoperatif yerleştirilmesi 
ve internal ilyak arterlere doğru ilerletilmesini içerir. Balonlar sezaryan histerektomi öncesinde bebeğin doğurtulmasını takiben aralıklı olarak 20 dakikaya kadar şişirilip söndürülebilir ve kan kaybını belirgin olarak azaltır, operatif alanı kuru tutar, klemplerin ve sütürlerin dikkatli konulmasına yardımcı olur. İşlem tecrübeli anjiografi uzmanı gerektirir ve postoperatif dönemde birkaç saat boyunca yerinde tutulabilir, postoperatif dönemdeki kanamalarda küçük pelvik damarların selektif embolizasyonu için de kullanılabilir. Balon kateterlerin çıkartılması da yine floroskopi altında yapılmalıdır [41, 42]. Her ne kadar sezaryan histerektomi öncesi kan kaybını azalttığı bazı çalışmalarda gösterilmiş olsa da balon oklüzyon işlemine bağlı arterial stent takılmasını veya bypass yapılmasını gerektirebilecek trombotik ve embolik komplikasyonlar da bildirilmiş olduğundan hastalara işlem öncesi balon oklüzyon uygulamasının riskleri hakkında detaylı bilgi verilmelidir [43]. Eğer intraoperatif olarak proflaktik internal iliak arter veya uterin arter embolizasyonu yapılması planlanıyorsa, doğumun floroskopi şartlarının sağlandığı bir ortamda yapılması ve bebeğin doğurtulmasını takiben arteriyel embolizasyon işleminin yapılması gerekmektedir [35-39].

\section{Intraoperatif yaklaşım}

Preoperatif ultrasonografide plasenta yapışma anomalisini düşündüren kötü prognostik bulguları olan hastalarda vertikal bir cilt insizyonu oluşturulması olası bir sezaryan histerektomi operasyonunu kolaylaştırması bakımından uygun bir cerrahi görüş alanı sağlayacağından obstetrikte sıklıkla kullanılan pfannenstiel insizyona tercih edilebilir. Mesane uterustan bir flep halinde ayrılabiliyorsa cerrahiyi kolaylaştırır. Plasentanın üst kısmından plasentaya zarar vermemeye özen gösterilerek vertikal bir uterin insizyon aç1lır ve fetüs doğurtulur. Preoperatif dönemde plasentanın tam lokalizasyonu ultrasonografi yardımı ile bakılarak plasentanın olmadığı uygun uterin insizyon yeri seçilebilir. İntraoperatif dönemdeki bulgular plasenta inkreta veya perkretayı işaret ediyorsa plasentanın sezaryanda çıkarılma girişimleri sıklıkla masif kanamaya sebep olduğından plasenta yerinde bırakılarak sezaryan histerektomiye geçilmelidir. Vakaların yaklaşık \%50'sinde hipogastrik arter ligasyonu kanamayı kontrol etmede başarısız bulunmuştur [44]. Eğer sezaryanda kanamayı durdurucu tedavi şekli olarak histerektomi yapılmasına karar verilirse, subtotal histerektomide servikal bölgeden kanama riskinin devam etmesi nedeni ile total histerektomi yapılması daha uygundur.

Sezaryanda plasenta çıkarıldıktan sonra plasentanın parsiyel olarak kanamaya sebep olacak şekilde uterusa yapışık olması nedeni ile meydana gelebilecek kanamanın medikal ve/veya cerrahi tedavilerle kontrol altına alınması durumunda uterus korunabilir. Tedavide medikal tedavi (uterotonikler, topikal hemostatik ajanlar), girişimsel radyolojik tedaviler, Bakri balon tamponad gibi mekanik yöntemler ve kanamayı durdurma amaçlı cerrahi girişimler yapılabilir [45]. Bir cerrahi yaklaşıma göre fokal olarak yapışık olan plasenta alanı kürete edilir ve bu bölgedeki kanamalı alan sütüre edilerek kanama durdurulabilir. Eğer bu kanamayı durdurmazsa fokal akreta içeren alana wedge rezeksiyon yapılıp oluşan uterin myometriyal defekt sütüre edilebilir [46-48]. Yerinde birakılan plasenta kanama ve enfeksiyon riski ile beraber seri ultrason muayeneleri ile takip edilir. Konservatif yönetimi takiben bir süre sonra pelvik damarlanma azalır ve plasentanın çıkarılması için daha sonra muhtemel yapılabilecek cerrahi tedaviyi kolaylaştırır.

Plasentas1 uterusta birakılan kadınlarda plasental rezorpsiyon ortalama 13.5 haftada olmuştur (4-60 hafta aras1) [49]. Kanda hCG seviyelerinin tespit edilemez seviyede olmas1 yerinde birakılan plasental dokunun komplet rezorpsiyonunu garanti etmez.

Hemodinamik olarak stabil hastalarda metotreksat tedavisinin başarılı kullanıldığı vakalar olmuştur. Ciddi enfeksiyon, gecikmiş vajinal kanama ve dissemine intravasküler koagülasyon meydana gelebilir ve cerrahi tedaviye ihtiyaç duyulabilir [50-52]. Metotreksat tedavisi sonrası bir sonraki gebeliği normal doğumla sonuçlanan bir vaka vardır. Şu anki bilgiler metotreksatın bu endikasyonda kullanımını tavsiye etmek için yeterli değildir. 
Sezaryanda plasenta yapışma anomalisi tespit edilen hastalarda fertilite koruyucu bir diğer cerrahi tedavi şekli plasentanın ve plasenta tarafından invaze edilmiş myometriyum kısmının rezeksiyonu ve oluşan myometrial defektin primer onarılmasıdır. $\mathrm{Bu}$ işlem uterin alt segmentin plasenta tarafından invaze edildiği plasenta previa vakalarında uygulanması önerilmemektedir [47].

Konservatif yönetim sonrası reprodüktif sonuçlar bu konuda yeterli data olmamasına rağmen suboptimaldir. Altta yatan endometrial anormallik düzeltilmemiş olduğundan ve postpartum küretaj nedeni ile artmış rekürren plasenta akreta ve intrauterin sineşi riski mevcuttur. Plasenta akretası olup konservatif tedavi görüp uterusu korunan 96 kadında yapılan retrospektif çok merkezli bir çalışmada 8 kadında ciddi intrauterin sineşi gelişmiş ve amenoreik görülmüştür, gebelik isteyen 27 kadından 24 tanesi gebe kalabilmiştir ve 21 doğumdan 6 tanesinde $(\% 28,6)$ plasenta akreta görülmüştür [53].

Plasenta akreta ile komplike olan gebeliklerin perinatal sonuçları hakkında çok fazla çalışma yoktur. Bir vaka- kontrol çalışmasında plasenta akretalı 310 hastada preterm doğum ve düşük doğum ağırlıklı bebek oranlarında belirgin artış bulunmuştur [54]. Son olarak, plasental implantasyon anomalilerine yaklaşımda klinik bir algoritma önerisi Tablo 1' de özetlenmiştir [55].

Tablo 1. Plasental implantasyon anomalilerinde klinik yönetim algoritması*

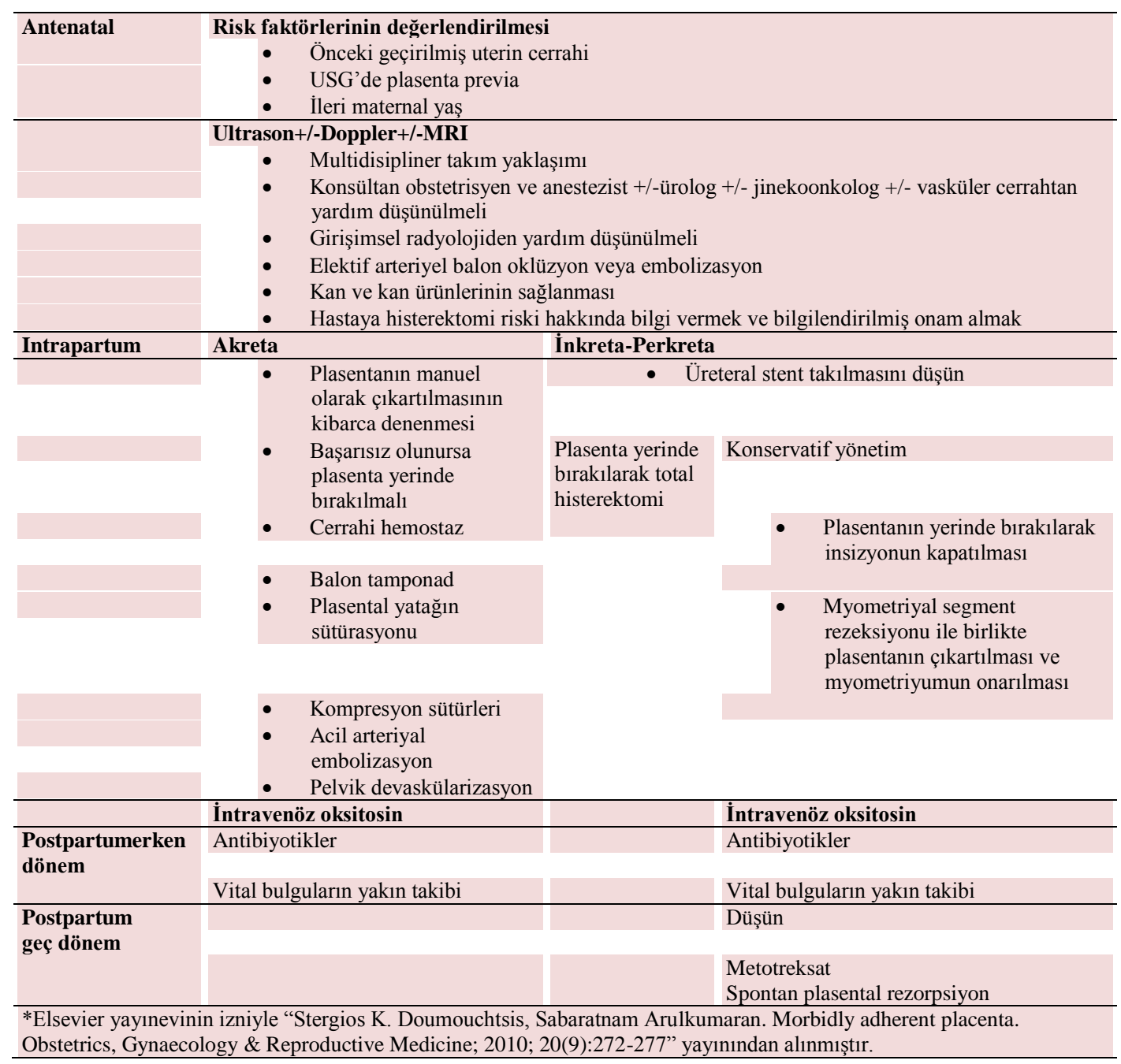

Sonuç olarak, plasental yapışma anomalileri ciddi maternal morbidite ve mortaliteye sebep olan, son yıllarda artan sezaryan oranlarına paralel olarak görülme sıklığı artan masif obstetrik kanama sebeplerinden biridir. Bu hastaların doğumu ile ilgili etkin bir 
yönetim planı oluşturmak için prenatal takip döneminde temel olarak ultrasonografik muayene ile plasental yapışma anomalisinden şüphelenilmesi çok önemlidir. Plasental invazyonun derecesi, hastanın klinik durumu, klinisyenin cerrahi tecrübesi, kliniğin şartları ve hastanın fertilite isteğinin bulunup bulunmamasına bağlı olarak uterus koruyucu cerrahiler veya sezaryan histerektomi yapılabilir. Kan ve kan ürünlerinin yoğun kullanımı, multidisipliner yaklaşım ve uygun vakalarda girişimsel radyolojik işlemlere erişilebilmesi bu hastaların klinik yönetiminde önem taşır. Fetal matüritenin tespit edilmesi halinde plasenta yapışma anomalisi olan hastaların 36. haftadan sonra uygun klinik şartlarının sağlanarak sezaryan ile doğuma alınmasının maternal morbidite ve mortaliteyi azalttı̆̆ından bu gebelik haftasından sonra hastaların uygun klinik şartların mevcut olduğu merkezlere gönderilmesi doğru bir yaklaşım olacaktır.

\section{Kaynaklar}

1. Knight M; UKOSS. Peripartum hysterectomy in the UK: management and outcomes of the associated haemorrhage. BJOG 2007; 114: 1380-7.

2. Norwitz ER. Defective implantation and placentation: laying the blueprint for pregnancy complications. Reprod Biomed Online 2006; 13: 591-9.

3. Silver RM, Landon MB, Rouse DJ, Leveno KJ, Spong CY, Thom EA, Moawad AH, Caritis SN, Harper M, Wapner RJ, Sorokin Y, Miodovnik M, Carpenter M, Peaceman AM, O'Sullivan MJ, Sibai B, Langer O, Thorp JM, Ramin SM, Mercer BM; National Institute of Child Health and Human Development Maternal-Fetal Medicine Units Network. Maternal morbidity associated with multiple repeat cesarean deliveries. Obstet Gynecol 2006; 107: 1226-32.

4. Rosen T. Placenta accreta and cesarean scar pregnancy: overlooked costs of the rising cesarean section rate. Clin Perinatol 2008; 35: 519-29.

5. Hoffman MK, Sciscione AC. Placenta accreta and intrauterine fetal death in a woman with prior endometrial ablation: a case report. J Reprod Med 2004; 49: 384-6.

6. Pron G, Mocarski E, Bennett J, Vilos G, Common A, Vanderburgh L; Ontario UFE Collaborative Group. Pregnancy after uterine artery embolization for leiomyomata: the Ontario multicenter trial. Obstet Gynecol 2005; 105: 67-76.

7. Rao KP, Belogolovkin V, Yankowitz J, Spinnato JA 2nd. Abnormal placentation: evidence-based diagnosis and management of placenta previa, placenta accreta, and vasa previa. Obstet Gynecol Surv 2012; 67: 503-19.

8. Warshak CR, Eskander R, Hull AD, Scioscia AL, Mattrey RF, Benirschke K, Resnik R. Accuracy of ultrasonography and magnetic resonance imaging in the diagnosis of placenta accreta. Obstet Gynecol 2006; 108: 573-81.

9. Levine D, Hulka CA, Ludmir J, Li W, Edelman RR. Placenta accreta: evaluation with color Doppler US, power Doppler US, and MR imaging. Radiology 1997; 205: 773-6.

10. Yang JI, Lim YK, Kim HS, Chang KH, Lee JP, Ryu HS. Sonographic findings of placental lacunae and the prediction of adherent placenta in women with placenta previa totalis and prior Cesarean section. Ultrasound Obstet Gynecol 2006; 28 : 178-82.

11. Warshak CR, Ramos GA, Eskander R, Benirschke K, Saenz CC, Kelly TF, Moore TR, Resnik R. Effect of predelivery diagnosis in 99 consecutive cases of placenta accreta. Obstet Gynecol 2010; 115: 65-9.

12. Comstock $\mathrm{CH}$. Antenatal diagnosis of placenta accreta: a review. Ultrasound Obstet Gynecol 2005; 26:89-96.

13. Comstock CH, Love JJ Jr, Bronsteen RA, Lee W, Vettraino IM, Huang RR, Lorenz RP. Sonographic detection of placenta accreta in the second and third trimesters of pregnancy. Am J Obstet Gynecol 2004; 190: 1135-40.

14. Comstock $\mathrm{CH}$, Lee W, Vettraino IM, Bronsteen RA. The early sonographic appearance of placenta accreta. J Ultrasound Med 2003; 22: 19-23. 
15. Twickler DM, Lucas MJ, Balis AB, Santos-Ramos R, Martin L, Malone S, Rogers B. Color flow mapping for myometrial invasion in women with a prior cesarean delivery. J Matern Fetal Med 2000; 9: 330-5.

16. Maldjian C, Adam R, Pelosi M, Pelosi M 3rd, Rudelli RD, Maldjian J. MRI appearance of placenta percreta and placenta accreta. Magn Reson Imaging 1999; 17: 965-71.

17. Kirkinen P, Helin-Martikainen HL, Vanninen R, Partanen K. Placenta accreta: imaging by gray-scale and contrast-enhanced color Doppler sonography and magnetic resonance imaging. J Clin Ultrasound 1998; 26: 90-4.

18. Grosvenor A, Silver R, Porter TF, Zempolich, K. Optimal management of placenta accreta. Am J Obste Gynecol 2007; 195: S82.

19. Lax A, Prince MR, Mennitt KW, Schwebach JR, Budorick NE. The value of specific MRI features in the evaluation of suspected placental invasion. Magn Reson Imaging 2007; 25: 87-93.

20. Butler EL, Dashe JS, Ramus RM. Association between maternal serum alphafetoprotein and adverse outcomes in pregnancies with placenta previa. Obstet Gynecol 2001; 97: 35-8.

21. Hung TH, Shau WY, Hsieh CC, Chiu TH, Hsu JJ, Hsieh TT. Risk factors for placenta accreta. Obstet Gynecol 1999; 93: 545-50.

22. Zelop C, Nadel A, Frigoletto FD Jr, Pauker S, MacMillan M, Benacerraf BR.Placenta accreta/percreta/increta: a cause of elevated maternal serum alphafetoprotein. Obstet Gynecol 1992; 80: 693-4.

23. Mazouni C, Gorincour G, Juhan V, Bretelle F. Placenta accreta: a review of current advances in prenatal diagnosis. Placenta 2007; 28: 599-603.

24. Zelop CM, Harlow BL, Frigoletto FD Jr, Safon LE, Saltzman DH. Emergency peripartum hysterectomy. Am J Obstet Gynecol 1993; 168: 1443-8.

25. Glaze S, Ekwalanga P, Roberts G, Lange I, Birch C, Rosengarten A, Jarrell J, Ross S. Peripartum hysterectomy: 1999 to 2006. Obstet Gynecol 2008; 111: 7328.

26. Bakri YN, Sundin T. Cystotomy for placenta previa percreta with bladder invasion. Urology 1992; 40: 580.

27. O'Brien JM, Barton JR, Donaldson ES. The management of placenta percreta: conservative and operative strategies. Am J Obstet Gynecol 1996; 175: 1632-8.

28. Estella NM, Berry DL, Baker BW, Wali AT, Belfort MA. Normovolemic hemodilution before cesarean hysterectomy for placenta percreta. Obstet Gynecol 1997; 90: 669-70.

29. Nagy CJ, Wheeler AS, Archer TL. Acute normovolemic hemodilution, intraoperative cell salvage and PulseCO hemodynamic monitoring in a Jehovah's Witness with placenta percreta. Int J Obstet Anesth 2008; 17: 159-63.

30. Grange CS, Douglas MJ, Adams TJ, Wadsworth LD. The use of acute hemodilution in parturients undergoing cesarean section. Am J Obstet Gynecol 1998; 178: 156-60.

31. Kreimeier U, Messmer K. Perioperative hemodilution. Transfus Apher Sci 2002; 27: 59-72.

32. Dubois J, Garel L, Grignon A, Lemay M, Leduc L. Placenta percreta: balloon occlusion and embolization of the internal iliac arteries to reduce intraoperative blood losses. Am J Obstet Gynecol 1997; 176: 723-6.

33. Paull JD, Smith J, Williams L, Davison G, Devine T, Holt M. Balloon occlusion of the abdominal aorta during caesarean hysterectomy for placenta percreta. Anaesth Intensive Care 1995; 23: 731-4.

34. Kidney DD, Nguyen AM, Ahdoot D, Bickmore D, Deutsch LS, Majors C. Prophylactic perioperative hypogastric artery balloon occlusion in abnormal placentation. AJR Am J Roentgenol 2001; 176: 1521-4.

35. Hong TM, Tseng HS, Lee RC, Wang JH, Chang CY.Uterine artery embolization: an effective treatment for intractable obstetric haemorrhage. Clin Radiol 2004; 
59: 96-101.

36. Ojala K, Perälä J, Kariniemi J, Ranta P, Raudaskoski T, Tekay A. Arterial embolization and prophylactic catheterization for the treatment for severe obstetric hemorrhage. Acta Obstet Gynecol Scand 2005; 84: 1075-80.

37. Salazar GM, Petrozza JC, Walker TG. Transcatheter endovascular techniques for management of obstetrical and gynecologic emergencies. Transcatheter endovascular techniques for management of obstetrical and gynecologic emergencies. Tech Vasc Interv Radiol 2009; 12: 139-47.

38. Chou MM, Hwang JI, Tseng JJ, Ho ES. Internal iliac artery embolization before hysterectomy for placenta accreta. J Vasc Interv Radiol 2003; 14: 1195.

39. Angstmann T, Gard G, Harrington T, Ward E, Thomson A, Giles W. Surgical management of placenta accreta: a cohort series and suggested approach. Am J Obstet Gynecol 2010; 202: 38.e1-9.

40. Dilauro MD, Dason S, Athreya S. Prophylactic balloon occlusion of internal iliac arteries in women with placenta accreta: literature review and analysis. Clin Radiol 2012; 67: 515-20.

41. Shrivastava V, Nageotte M, Major C, Haydon M, Wing D. Case-control comparison of cesarean hysterectomy with and without prophylactic placement of intravascular balloon catheters for placenta accreta. Am J Obstet Gynecol 2007; 197: 402.e1-5.

42. Bodner LJ, Nosher JL, Gribbin C, Siegel RL, Beale S, Scorza W. Balloonassisted occlusion of the internal iliac arteries in patients with placenta accreta/percreta. Cardiovasc Intervent Radiol 2006; 29: 354-61.

43. Greenberg JI, Suliman A, Iranpour P, Angle N. Prophylactic balloon occlusion of the internal iliac arteries to treat abnormal placentation: a cautionary case. Am J Obstet Gynecol 2007; 197: 470.e1-4.

44. Sziller I, Hupuczi P, Papp Z. Hypogastric artery ligation for severe hemorrhage in obstetric patients. J Perinat Med 2007; 35: 187-92.

45. American College of Obstetricians and Gynecologists.ACOG Practice Bulletin: Clinical Management Guidelines for Obstetrician-Gynecologists Number 76, October 2006: postpartum hemorrhage. Obstet Gynecol 2006; 108: 1039-47.

46. Riggs JC, Jahshan A, Schiavello HJ. Alternative conservative management of placenta accreta. A case report. J Reprod Med 2000; 45: 595-8.

47. Schnorr JA, Singer JS, Udoff EJ, Taylor PT. Late uterine wedge resection of placenta increta. Obstet Gynecol 1999; 94: 823-5.

48. Palacios Jaraquemada JM, Pesaresi M, Nassif JC, Hermosid S.Anterior placenta percreta: surgical approach, hemostasis and uterine repair. Acta Obstet Gynecol Scand 2004; 83: 738-44.

49. Sentilhes L, Ambroselli C, Kayem G, Provansal M, Fernandez H, Perrotin F, Winer N, Pierre F, Benachi A, Dreyfus M, Bauville E, Mahieu-Caputo D, Marpeau L, Descamps P, Goffinet F, Bretelle F. Maternal outcome after conservative treatment of placenta accreta. Obstet Gynecol 2010; 115: 526-34.

50. Pinho S, Sarzedas S, Pedroso S, Santos A, Rebordão M, Avillez T, Casal E, Hermida M. Partial placenta increta and methotrexate therapy: three case reports. Clin Exp Obstet Gynecol 2008; 35: 221-4.

51. Raziel A, Golan A, Ariely S, Herman A, Caspi E. Repeated ultrasonography and intramuscular methotrexate in the conservative management of residual adherent placenta. J Clin Ultrasound 1992; 20: 288-90.

52. Legro RS, Price FV, Hill LM, Caritis SN. Nonsurgical management of placenta percreta: a case report. Obstet Gynecol 1994; 83: 847-9.

53. Sentilhes L, Kayem G, Ambroselli C, Provansal M, Fernandez H, Perrotin F, Winer N, Pierre F, Benachi A, Dreyfus M, Bauville E, Mahieu-Caputo D, Marpeau L, Descamps P, Bretelle F, Goffinet F. Fertility and pregnancy outcomes following conservative treatment for placenta accreta. Hum Reprod 2010; 25: 2803-10. 
54. Gielchinsky Y, Mankuta D, Rojansky N, Laufer N, Gielchinsky I, Ezra Y. Perinatal outcome of pregnancies complicated by placenta accreta. Obstet Gynecol 2004; 104: 527-30.

55. Stergios K. Doumouchtsis, Sabaratnam Arulkumaran. Morbidly adherent placenta. Obstetrics, Gynaecology \& Reproductive Medicine 2010; 20: 272-7. 